\title{
O Município e a Saúde: Reflexões Sobre as Balizas Impostas Pelo Ordenamento Jurídico Vigente Para A Atuação Do Poder Público local
}

THE LOCAL GOVERNMENT AND THE HEALTH: REFLECTIONS ON THE LEGAL GUIDELINES FOR THE PERFORMANCE OF THE MUNICIPALITIES

Claudia Aguiar de Siqueira ${ }^{\text {* }}$

\section{RESUMO}

O artigo tem como proposta o delineamento do papel reservado ao município dentro do sistema cooperativo e integrado de ações governamentais no âmbito da saúde inaugurado pela Constituição promulgada em outubro de 1988. A análise partirá de um resumo das diretrizes constitucionais aplicáveis, enfocando o contraste entre as competências executiva e legiferante na matéria, após o que serão especificamente abordados os temas da vigilância sanitária e da saúde suplementar.

\section{Palavras-chave} mentar.

Município, Competência, Saúde, Vigilância Sanitária, Saúde Suple-

\section{ABSTRACT}

The purpose of the article is to design the role to be played by the Municipalites under the integrated and cooperative sistem of governmental health actions established by the Brazilian Federal Constitution of October

(*) Advogada, Consultora do Instituto Brasileiro de Administração Municipal - IBAM, ex-integrante da carreira federal de Especialista em Políticas Públicas e Gestão Governamental (ENAP/1999), Mestre em Teoria Geral do Estado e Direito Constitucional (PUC/RJ), ex-doutoranda em Ciência Política do Instituto Universitário de Pesquisas do Rio de Janeiro (IUPERJ). 
1988. The analysis comprises a summary of the applicable constitutional guidelines, focusing the contrast between the executive and the legislative given competencies, and also sanitary surveillance and supplementary health services institutional approach.

\section{Key-words}

Municipality, Governmental Competencies, Health, Sanitary Surveillance, Supplementary Heath Services.

\section{INTRODUÇÃO}

Transcorridos 14 anos de promulgação da atual Constituição Federal, persiste a polêmica em torno dos limites impostos à atuação municipal em matéria de saúde. $O$ assunto é recorrente em consultas formuladas aos institutos dedicados à prestação de assessoria aos municípios, que vêm sendo solicitados a abordar o tema tanto sob o prisma do exercício do poder de polícia sanitária quanto sob o da defesa do cidadão em face dos abusos praticados pelos estabelecimentos privados de prestação de serviços de saúde. A proposta deste artigo é traçar, de forma singela, o papel reservado ao município dentro do sistema cooperativo e integrado de ações governamentais visando a promoção da saúde inaugurado pela Constituição de 1988, com o objetivo de auxiliar as autoridades locais no escorreito desempenho desta que se destaca como uma de suas mais importantes atribuições.

\section{A PROMOÇÃO DA SAÚdE NA CONSTITUIÇÃO FEDERAL DE 1988: O PAPEL DO MUNICÍPIO}

A CF/88 prevê o estabelecimento de um esquema de ações concertadas entre os entes federativos em matéria de promoção da saúde, como se pode inferir da dicção do art. 23, II, verbis:

Art. 23. É competência comum da União, dos Estados, do Distrito Federal e dos Municípios:

\section{I...I}

II. cuidar da saúde e assistência pública, da proteção e garantia das pessoas portadoras de deficiência;

O Capítulo II do Título VIII da Carta Magna, que trata da Ordem Social, dispõe, especificamente, sobre a Seguridade Social, que compreende a saúde (Seção II), a previdência social (Seção III) e a assistência social (Se- 
ção IV). O caráter sistêmico como pedra de toque do panorama institucional se confirma nos arts. 194 e 195, que integram a Seção I (disposições gerais sobre a seguridade social). Com efeito, o art. 194 explicita as premissas e os objetivos do sistema brasileiro de seguridade social, preconizando a iniciativa indistinta dos poderes públicos e da sociedade. Quanto ao art. 195, que trata da delicada questão do custeio do sistema, menciona, expressamente, entre outros, o somatório de recursos provenientes dos orçamentos da União, dos Estados, do Distrito Federal e dos Municípios, na forma detalhada nos seus $\S \S 1^{\circ}$ e 10.

Por sua vez, os arts. 196 e 197 - que estão na seção dedicada à saúde - fazem alusão genérica ao papel preponderante do poder público na matéria, a par da admissibilidade da participação de pessoas físicas ou jurídicas de direito privado na atividade, que se pode dar tanto em nome próprio quanto na qualidade de delegatárias de serviços, em caráter complementar, no âmbito do Sistema Único de Saúde - SUS ${ }^{(1)}$. Merece realce o fato de que, em sede de SUS, afasta-se a entrega, ao particular, da gestão dos serviços de saúde. Sua participação restringese, apenas e tão-somente, à realização de atividades-meio, como, por exemplo, limpeza e vigilância, e ao fornecimento de serviços técnicoespecializados de saúde específicos, hipótese em que, repise-se, o objeto da transferência será apenas a execução material da atividade, não a sua gestão operacional, que continuará a ser titularizada pela entidade delegante ${ }^{(2)}$.

Dúvida não há, portanto, quanto à imposição constitucional, a todas as unidades federativas, de participar ativamente na promoção da saúde, na forma sintetizada pelo já citado art. 23, II. Dentro desse panorama, a descentralização - com ênfase na municipalização - desponta como um dos princípios basilares que orientam a construção do SUS, assumindo o Município, na nova ordem, a posição de titular de função própria, em contraste com o papel subalterno, de mero delegatário de funções transferidas por outras esferas federativas, que the fora conferido no âmbito do antigo Sistema Unificado e Descentralizado de Saúde - SUDS. Ressalte-se que o constituinte deu tratamento especial ao assunto, de sorte a afastar qualquer dúvida eventualmente remanescente sobre a competência municipal originária em matéria de saúde. Colacione-se, a respeito, o inciso próprio do art. 30 da Constituição Federal, dispositivo que sistematiza as competências do município, sem prejuizo de outras eventualmente constantes do texto constitucional de forma esparsa:

(1) Vide arts. 199, da CF/88, e $4^{\circ}, \S 2^{\circ}, 20$ a 26, da Lei n. 8.080/90 - Lei Orgânica da Saúde, bem como o item 3 deste artigo.

(2) Consulte-se, a respeito, DI PIETRO, Maria Sylvia Zanella. Parcerias na Administração Pública: Concessão, Permissão, Franquia, Terceirização e outras formas. São Paulo, Atlas, 1996. 
Art. 30. Compete aos Municípios:

\section{I...l}

VII. prestar, com a cooperação técnica e financeira da União e do Estado, serviços de atendimento à saúde da população;

Para o alcance dos objetivos declinados no preâmbulo deste artigo, será indispensável traçar um painel, para demonstrar a originalidade do sistema traçado pela Constituição da República no que tange às ações e normas relativas à saúde. Como se evidenciará, as peculiaridades inerentes ao referido sistema geram para o município a obrigação de respeitar nichos legislativos pertencentes a outras entidades da Federação, sem prejuízo de suas atribuições executivas plenas quanto ao tema, que incluem, por certo, zelar amplamente pela observância dos regramentos de proveniência alienígena. Será abordada, também, a controvérsia acerca da faculdade municipal supletiva de lançar normas sobre saúde, que se manifesta de forma especial no exercício regular do poder de polícia sanitária, objeto do item 4 destas reflexões.

\section{AS ENTIDADES FEDERATIVAS E A PROMOÇÃO DA SAÚDE: COMPETÊNCIA EXECUTIVA X COMPETÊNCIA LEGIFERANTE}

Parágrafos acima, já se registrou o mandamento constitucional básico que rege a competência para atuar no campo da promoção da saúde: o art. 23, II, que estabelece, taxativamente, a competência executiva comum, entregue a todas as esferas da Federação. $O$ aresto é cristalino, não oferecendo nenhuma dificuldade interpretativa.

Igualmente, comentários já foram tecidos no item anterior a respeito da articulação das entidades federativas preconizada pelo legislador constituinte, com especial ênfase para a descentralização e a municipalização dos serviços de saúde, bem como sobre a possibilidade e as limitações impostas à participação da iniciativa privada no setor. Nesse diapasão, chama-se a atenção para o fato de que a sincronização executiva entre os componentes da Federação em matéria de saúde corporificou-se no Sistema Único de Saúde - SUS, cujo esboço, traçado no art. 198 da Constituição Federal, foi plenamente desenvolvido pela edição da Lei n. 8.080/90 - Lei Orgânica da Saúde ${ }^{(3)}$. $O$ art. $4^{\circ}$ da referida lei enumera os participantes do sistema:

Art. 4ㅇ O conjunto de ações e serviços de saúde, prestados por órgãos e instituições públicas federais, estaduais e municipais, da Administração direta e indireta e das fundações mantidas pelo Poder Público, constitui o Sistema Único de Saúde (SUS).

(3) "Dispõe sobre as condições para a promoção, proteção e recuperação da saúde, a organização e o funcionamento dos serviços correspondentes e dá outras providências". 
$\S 1^{\circ}$ Estão incluídas no disposto neste artigo as instituições públicas federais, estaduais e municipais de controle de qualidade, pesquisa e produção de insumos, medicamentos, inclusive de sangue e hemoderivados, e de equipamentos para saúde.

$\S 2$ A iniciativa privada poderá participar do Sistema Único de Saúde (SUS), em caráter complementar.

Ultrapassada a questão da titularidade da competência executiva em matéria de saúde, desloca-se o foco para a competência legiferante, estribada no art. 24, XII, da CF/88, abaixo transcrito para maior comodidade:

Art. 24. Compete à União, aos Estados e ao Distrito Federal legislar concorrentemente sobre:

\section{I...I}

XII. previdência social, proteção e defesa da saúde;

Aparentemente a Carta Magna teria excluído o município do elenco de atores aptos a dispor sobre proteção e defesa da saúde. Contudo, a questão vertente não comporta posicionamentos monolíticos. Ao contrário, as nuances do problema sugerem o recurso ao método sistemático de interpretação do texto constitucional, de sorte a captar a essência da Carta em sede de competência municipal(4). Com a utilização dessa ferramenta, inevitavelmente chega-se à conclusão de que o invocado mandamento, a despeito do que possa parecer, não se traduz em total inaptidão municipal para legislar sobre saúde.

Ocorre que, analisando o assunto à luz dos incisos I e II do art. 30 da $\mathrm{CF} / 88$, segundo os quais ao município compete legislar sobre assuntos de interesse local, suplementando a legislação federal e a estadual no que couber, a boa doutrina, majoritariamente, vem considerando implicitamente designada ao poder público local a faculdade de normatizar em sede de saúde, desde que seu desempenho se paute pelo princípio da predominância do interesse local, e, também, seja circunscrito à adaptação de normas de proveniência federal e estadual à realidade comunal(5). Não poderia ser diferente. Dado o robusto rol de atribuições constitucionalmente cometidas às municipalidades em matéria de saúde, aliado a um contexto de ampla heterogeneidade das esferas federativas menores, a conformação das normas federais e estaduais às peculiaridades locais, por vezes, faz-se imperativa. Subtrair dos municípios tal faculdade, além de ir contra o espírito do art. 30, II, da CF/88, por certo contribuiria sobremaneira para tomar letra morta os mandamentos da Lei Maior e da Lei n. 8.080/90 referentes à descentralização do SUS.

(4) BARROSO, Luís Roberto. Interpretação e Aplicação da Constituição: fundamentos de uma dogmática constitucional transformadora. São Paulo, Saraiva, $4^{a}$ ed., 2002.

(5) Veja-se, por exemplo, MORAES, Alexandre. Competências administrativas e legislativas para vigilância sanitária de alimentos. In: Revista de Informação Legislativa, n. 145, jan/mar 2000, p. 77-85. 


\section{O MUNICÍPIO E A VIGILÂNCIA SANITÁRIA}

A vigilância sanitária se insere dentro do espectro de ações destinadas à proteção e defesa da saúde. Registre-se sua expressa inclusão no campo de atuação do SUS - e, por via de conseqüência, dos integrantes do Sistema - na forma do art. 6o da Lei n. 8.080/90:

Art. 6º Estão incluídas ainda no campo de atuação do Sistema Único de Saúde (SUS):

I - a execução de ações:

a) de vigilância sanitária;

\section{l...l}

$\S 1^{\circ}$ Entende-se por vigilância sanitária um conjunto de ações capaz de eliminar, diminuir ou prevenir riscos à saúde e de intervir nos problemas sanitários decorrentes do meio ambiente, da produção e circulação de bens e da prestação de serviços de interesse da saúde, abrangendo:

I - o controle de bens de consumo que, direta ou indiretamente, se relacionem com a saúde, compreendidas todas as etapas e processos, da produção ao consumo; e

II - o controle da prestação de serviços que se relacionam direta ou indiretamente com a saúde.

Sendo o município esfera federativa de interação privilegiada com o cidadão, seu papel na vigilância sanitária é extremamente relevante. Com efeito, o poder de polícia sanitária se destaca no rol de atribuições municipais, concretizando-se, na feliz definição de Hely Lopes Meirelles, na adoção de normas e medidas específicas, requeridas por situações de perigo presente ou futuro, que lesem ou ameacem lesar a saúde e a segurança dos indivíduos e da comunidade. Nesse panorama, as normas sanitárias municipais têm como objetivo precípuo o controle técnico-funcional das edificações particulares e dos recintos públicos, bem como dos gêneros alimentícios destinados ao consumo local(6).

Estabelecidos o papel proativo do município quanto à vigilância sanitária, e a complexidade e a diversidade da realidade municipal brasileira, aplicam-se, como se vê, à perfeição, as supramencionadas teorias da predominância do interesse local e da necessidade de suplementação da legislação federal e estadual, para fins de adaptação, as especificidades da comunidade, para justificar a eventual edição de normas municipais so-

(6) MEIRELLES, Hely Lopes. Direito Administrativo Brasileiro. São Paulo, Editora Revista dos Tribunais, $15^{\mathrm{a}}$ ed., 1990. 
bre o assunto, pois, certamente, as necessidades dos municípios nesse particular primam pela disparidade. No entanto, é certo que tais normas sempre serão tributárias daquelas provenientes da União, notadamente das Leis ns. $6.360 / 76^{(7)}$ e $9.782 / 99^{(8)}$. Não se afaste, também, evidentemente, a imperativa observância, por parte dos municípios, das normas estaduais sobre vigilância sanitária, uma vez que o assunto se situa no campo da competência concorrente, submetido, por conseguinte, às regras do art. 24 da Constituição Federal.

Convém chamar a atenção para o fato de que incumbe às autoridades locais cumprir e fazer cumprir, por meio do corpo fiscalizatório local, as normas de vigilância sanitária emanadas do Estado e da União.

\section{O MUNICÍPIO E A SAÚDE SUPLEMENTAR: A DEFESA DO CIDADÃO EM FACE DE ATITUDES ABUSIVAS DOS AGENTES PRIVADOS DE SAÚDE}

A Constituição Federal, por meio de seu art. 199, admite expressamente a participação da iniciativa privada na assistência à saúde. Quando o serviço em foco é prestado ao cidadão por força de sua adesão a planos ou seguros privados de saúde, torna-se, incontestavelmente, objeto da atividade regulatória federal, conforme as competências inscritas nos arts. 24 , XII, e 197, da Constituição da República, dispositivos regulamentados pelas Leis ns. 9.656/98 (versa sobre os planos e seguros privados de saúde) e 9.961/00 (cria a Agência Nacional de Saúde Suplementar - ANS).

O tema se reveste de especial relevância, pois há uma profusão de iniciativas legislativas, no âmbito de diversos municípios brasileiros, visando coibir a prática da cobrança de depósito antecipado para fins de atendimento hospitalar, seja em casos de urgência e emergência, seja em casos de internação programada. Essas exigências, notoriamente, ainda são recorrentes no universo dos usuários de planos e seguros de saúde, apesar da sua flagrante improcedência.

Nos termos do art. 12, V, c, da Lei n. 9.656/98, as operadoras de planos ou seguros privados de saúde não podem impor carência superior a 24 horas para a cobertura do atendimento de casos de emergência e urgência. A exigência de prestação de caução, nesses casos, será interpretada como negativa de cobertura. Essa hipótese, assim como a aludida prática iníqua da exigência de depósito prévio para a realização de internação programada,

(7) "Dispõe sobre a Vigilância Sanitária a que ficam sujeitos os medicamentos, as drogas, os insumos farmacêuticos e correlatos, cosméticos, saneantes e outros produtos e dá outras providências".

(8) "Define o Sistema Nacional de Vigilância Sanitária, cria a Agência Nacional de Vigilância Sanitária e dá outras providências". 
deverão ser denunciadas à aludida autarquia especial federal, a quem competirá instaurar o respectivo procedimento fiscalizatório. A comprovação da tentativa de frustração de cobertura poderá redundar no descredenciamento do prestador de serviços de saúde por parte das operadoras de planos ou seguros de saúde, e, em última análise, em punição destas, caso se comprove sua conivência com tais práticas abusivas.

Por outro lado, o município constantemente se defronta com o problema dos usuários do SUS, que, em situações de risco de vida, eventualmente recorrem à rede privada de prestadores de serviços de saúde (hospitais e clínicas). Nesse ponto, traz-se ao debate o conceito de ressarcimento, compensação devida entre o Sistema Único de Saúde e os prestadores privados desses serviços, na forma da lei. $O$ ressarcimento tem duas direções, sendo a primeira devida pelo SUS ao prestador privado de serviços de saúde, e a segunda devida pelo operador de planos ou seguros privados de saúde ao SUS, quando seus associados são atendidos pelo sistema público. A inovação se encontra apenas na segunda hipótese, versada pelo art. 32 da Lei n. 9.656/98, pois os prestadores privados de serviços de saúde já recebiam, regularmente, pelos serviços eventualmente prestados aos usuários do sistema público, de acordo com as tabelas de procedimentos fixadas pelo Ministério da Saúde.

No entanto, sob a alegação de inexistência de compensação financeira adequada, é comum a negativa de atendimento a usuários do SUS por parte dos prestadores privados de serviços de saúde, situação que coloca em risco a vida de muitos cidadãos. Esse comportamento não é albergado pelo arcabouço legal pátrio, não somente por ser este regido pela lógica da universalidade do direito á saúde, mas também ante a perda - real ou potencial - de vidas humanas daí decorrente. Computase a existência de inúmeros julgados capitulando a conduta do profissional de saúde que se recusa a prestar atendimento na hipótese configurada como crime de omissão de socorro (vide Tribunal de Alçada Criminal de São Paulo, Julgados, 83/321; RT, 512/389; Tribunal de Justiça de Santa Catarina, RT, 511/427). Há, inclusive, enquadramento da situação em tela como homicídio culposo (vide Tribunal de Alçada Criminal de São Paulo, RT, 521/432).

De todo o exposto, resulta que, à luz das normas vigentes, as situações prequestionadas reclamam tratamento específico e individual, com o recurso aos órgãos administrativos, policiais e de defesa do consumidor competentes, entre os quais se inclui o Ministério Público. Mesmo instado a enfrentar as dificuldades eventualmente encontradas pela população em dar pleno cumprimento aos preceitos constitucionais e legais que propugnam pela universalidade e a intangibilidade do direito à saúde, ao município é vedado legislar sobre saúde suplementar, eis que o tema, como visto, é afeto à União. 


\section{CONCLUSÕES}

Compulsadas todas as ilações efetuadas ao longo do presente texto, é possível inferir o seguinte:

- a questão dos limites da atuação municipal em saúde ainda suscita controvérsias entre os agentes políticos e administrativos locais;

- a Constituição da República, prospectivamente, propõe um sistema de ações integradas dos entes federativos na área da saúde, conferindo ao município papel de destaque em virtude da idéia de descentralização de ações que anima o projeto do Sistema Único de Saúde - SUS;

- em matéria de saúde, há competência executiva plena de todas as entidades federativas, além de competência legislativa concorrente, pela qual se faculta ao município legislar em caráter suplementar, dentro do princípio da predominância do interesse local, principalmente quanto a assuntos relativos à vigilância sanitária;

- a competência legislativa supletiva municipal em matéria de vigilância sanitária se subordina às regras federais e estaduais incidentais, por cuja observância, inclusive, deve zelar o corpo fiscalizatório da administração local;

- eventuais abusos praticados pelos prestadores privados dos serviços de saúde ou pelas operadoras de planos e seguros de saúde devem ser tratados no âmbito dos órgãos policiais, administrativos e de defesa do consumidor competentes; e

- o município não possui competência para dispor sobre saúde suplementar. 